\title{
PERANCANGAN ILUSTRASI DONGENG SI KANCIL DAN SI KERA UNTUK ANAK USIA 4-6 TAHUN
}

\author{
Citra Kemala Putri ${ }^{1}$, Dwi Agustini Indriani ${ }^{2}$ \\ Prodi S1 Desain Komunikasi Visual, Fakultas Komunikasi dan Desain, \\ Universitas Informatika dan Bisnis Indonesia \\ citrakemala@unibi.ac.id ${ }^{1}$, da.indriani@mhs.ac.id ${ }^{2}$
}

\begin{abstract}
Abstrak
Buku Dongeng Si Kancil di Indonesia pada umumnya memuat cerita rekaan yang terkesan egois sehingga kurang baik disampaikan untuk anak usia dini. Sebagai contoh, murid TKQ Miftahul Hidayah familiar dengan dongeng Si Kancil yang memiliki sifat yang tidak baik, yaitu menipu Buaya agar bisa sampai di seberang sungai, serta lebih banyak mengenal Si Kancil melalui tayangan televisi buatan luar negri daripada dongeng di media cetak buatan Indonesia. Peneliti menggunakan metode kualitatif dan kuantitatif dalam mengolah fenomena ini. Teknik pengumpulan data dilakukan dengan wawancara, observasi, studi literatur dan kuesioner. Perancangan ini dibuat agar anak-anak usia dini umumnya, dan khususnya murid TKQ Miftahul Hidayah lebih mengenal dongeng Si Kancil khas Indonesia dengan ilustrasi dan narasi yang sesuai dengan anak-anak. Sehingga dapat mengedukasi moral anak-anak melalui dongeng Si Kancil yang telah diubah pandangannya menjadi karakter Si Kancil yang lebih baik.
\end{abstract}

Kata Kunci : dongeng, Kancil, anak usia dini, ilustrasi, narasi

\begin{abstract}
The Fabel Story of Kancil in Indonesia generally contains a fictional story that has bad image so it is poorly delivered for early childhood. For example, TKQ student Miftahul Hidayah is familiar with the story of Kancil which has bad character, such as deceiving Crocodile to get across the river, and more familiar about The Story of Kancil through foreign-made television shows than fairy tales in Indonesianmade print media. Researchers use qualitative and quantitative methods in processing this phenomenon. Data collection techniques were conducted by interview, observation, literature study and questionnaire. This design is made for children of early age generally, and especially students TKQ Miftahul Hidayah which is more familiar with the typical Indonesian story of Kancil that came along with illustrations and narratives that are appropriate to children. So that it can educate the moral of the children through the story of the Kancil which has changed its view into the better character of Kancil.
\end{abstract}

Keywords: tale, Kancil, early childhood, illustration, narrative

\section{PENDAHULUAN}

Masyarakat Indonesia di zaman dahulu giat menanamkan nilai-nilai adat istiadat dan beragam budaya melalui cerita rakyat yang diwariskan secara turun temurun, yaitu berupa dongengdongeng. Buku Cara Pintar Mendongeng, menuturkan bahwa: "Dongeng adalah cerita rekaan yang sering diidentikkan sebagai suatu cerita bohong, bualan, khayalan, atau cerita yang mengada-ada" (Asfandiyar, 2009:19). Cerita rakyat yang mulanya milik suatu daerah saja, kini berkembang dan tersebar sebagai budaya bangsa yang menggunakan Bahasa Indonesia. Salah satu dongeng yang cukup dikenal oleh masyarakat, khususnya anak-anak Indonesia adalah Dongeng Fabel Si Kancil. 
Dongeng fabel adalah dongeng tentang kehidupan binatang yang digambarkan bisa bicara seperti manusia. Cerita-cerita fabel sangat luwes digunakan untuk menyindir perilaku manusia tanpa membuat manusia tersinggung (Asfandiyar, 2009:86)

Dongeng-dongeng mengenai $\mathrm{Si}$ Kancil menceritakan petualangan seekor kancil dan hewan lainnya di dalam hutan. Kancil merupakan hewan asli Jawa yang umum dikenal oleh sebagian besar masyarakat sebagai makhluk protagonis yang lemah namun cerdik dengan cara mengelabui binatang lain yang lebih kuat darinya, seperti buaya, gajah, kera, dan lain-lain.

Si Kancil menjadi tokoh yang baik dalam berbagai judul cerita, seperti Si Kancil Mencuri Mentimun, Si Kancil dan Buaya, Si Kancil dan Burung Puyuh, Kancil Menipu Kera, dan masih banyak lagi. Dongeng tersebut memberikan pelajaran bahwa orang yang lemah bisa mengalahkan orang lain dengan akal pikirannya melalui cara 'berbohong' disertai alasan untuk kebaikan. Si Kancil Mencuri Mentimun contohnya, terdapat pula versi lagu dengan cerita yang sama, dengan lirik sebagai berikut:

Si kancil anak nakal

Suka mencuri timun

Ayo lekas ditangkap

Jangan diberi ampun

Dengan demikian, dongeng $\mathrm{Si}$ Kancil sebaiknya mendapat pertimbangan bila ingin diberikan kepada anak-anak, khususnya kepada anak-anak usia dini. Dari hasil wawancara peneliti dengan pendongeng, Ibu In In, didapat kesimpulan bahwa konten Dongeng Kancil Menipu Kera perlu diubah. Mulai dari tema, karakter tokoh Si Kancil, hingga penggunaan narasi yang tepat sehingga pesan moral yang terdapat di dalam dongeng dapat tersampaikan kepada anak-anak. Perubahan ini disesuaikan dengan teori perkembangan anak usia dini yang berkaitan dengan teori visual dan teori sastra anak agar visual buku dongeng Si Kancil dapat menyampaikan pesan moral yang ada dalam cerita secara efektif dan meningkatkan minat membaca anak-anak terhadap dongeng khas Indonesia.

\section{METODE PENELITIAN}

Peneliti menggunakan metode kualitatif dan kuantitatif atau mix method (metode campuran) dalam perancangan ini. Metode ini dianggap peneliti merupakan metode yang sesuai dalam menganalisis sebuah masalah dan fenomena.

Metode kualitatif adalah pendekatan yang di dalam usulan penelitian, proses, hipotesis, turun ke lapangan, analisis data, dan kesimpulan data sampai dengan penulisannya mempergunakan aspek-aspek kecenderungan, non perhitungan numerik, situasional deskriptif, interview mendalam, analisis bola salju dan story (Lukas, 2002:125).

Metode kualitatif yang dilakukan dalam penelitian mencakup wawancara dan observasi. Wawancara diantaranya dilakukan kepada pendongeng Ibu In In dan observasi dilakukan terhadap murid dan orangtua murid TKQ Miftahul Hidayah. Metode ini dilakukan untuk mengetahui masalah tentang dongeng Si Kancil untuk anakanak usia 4-6 tahun secara objektif.

Metode kuantitatif adalah pendekatan yang menggunakan aspek pengukuran, perhitungan dan kepastian numerik dimulai dari usulan penelitian, proses, hipotesis, turun ke lapangan, analisis data dan kesimpulan data sampai dengan penulisannya (Lukas, 2002:125). Metode kuantitatif yang digunakan adalah angket yang diberikan kepada orangtua TKQ Miftahul Hidayah untuk mengetahui banyaknya anak yang suka membaca buku dongeng dan kecenderungan desain dongeng fabel yang disukai anak-anak.

\section{PEMBAHASAN}

Sastra pada anak terbagi ke dalam beberapa jenis. Sastra atau bacaan anak secara umum meliputi: “(1) Buku bergambar; (2) Cerita rakyat (binatang, dongeng, legenda, atau mite); (3) Fiksi sejarah; (4) Fiksi realistik; (5) Fiksi ilmiah; (6) Cerita fantasi; dan (7) Biografi" (Mursini, 2009:4).

Sastra anak merupakan salah satu cara untuk menarik anak agar gemar membaca buku. Beberapa hal yang harus diperhatikan dalam membuat sastra anak yang dapat dijadikan pertimbangan para pembuat buku cerita maupun 
dikutip dalam jurnal Kontribusi Sastra Bagi AnakAnak, antara lain:

(1) Format buku bagi buku anak ditulis dalam Format Kuatro. Itulah sebabnya bacaan untuk anak-anak disebut sebagai Big Books atau buku besar;

(2) Cara penulisan yang mengacu pada tulisan maupun gambar yang disajikan. Sajian tulisan dan gambar itu pun digarap secara berimbang, bahkan biasanya sajian gambarnyalah yang lebih kuat

(3) Penyajiannya selain mempertimbangkan ukuran huruf dan kemudahan identifikasi huruf, kekayaan gambar, juga memperhatikan penggarapan aneka warna dalam bentuk sajian gambar yang hidup dan menarik;

(4) Bahasa yang digunakan untuk anak-anak ditinjau dari bahasa yang digunakan, antara lain: mengandung kata-kata konkret, katakata dapat membentuk perpautan bunyi sehingga menarik dan enak untuk dibaca, menggunakan kalimat yang sederhana, penanda hubungan kalimat yang satu dan yang lain tampil secara eksplisit;

(5) Isi bacaan teks sastra anak itu berupa cerita, sebaiknya menggunakan alur yang sederhana saja, tidak terlalu banyak melibatkan tokoh cerita, peristiwa yang digambarkan sederhana dan jelas, karena hanya berfokus pada satu peristiwa. Peristiwa itu pun dikembangkan menuju klimaks dan penyelesaian yang menyenangkan anak.

Berdasarkan jabaran di atas, peneliti menekankan rancangan pada ilustrasi yang menjadi kekuatan dari cerita si Kancil dengan mempertimbangkan warna dan gaya visual yang menarik. Sementara sajian tulisan dibuat singkat, padat dan jelas dengan menggunakan huruf yang sesuai dengan standar keterbacaan target audiens.

\section{OBSERVASI KARYA SEJENIS}

Peneliti melakukan observasi pada beberapa buku dongeng Si Kancil yaitu Buku Dongeng Pengantar Tidur Dongeng Si Kancil Pengarang Tira Ikranegara, Buku Kancil dan Raja Hutan karya Suyadi, Buku Dongeng Anak Dunia karya
Syaff Banta, Buku Si Cerdik Kancil Sabuk Nabi Sulaiman karya Heru Yuwono, dan Buku Si Kancil Mencuri Mentimun karya Dua Bahasa. Peneliti menyimpulkan bahwa 4 dari 5 buku Si Kancil menggambarkan tokoh kancil yang melakukan tipuannya tersebut untuk kepentingannya sendiri, sedangkan satu buku lainnya menjelaskan alasan Kancil menipu adalah untuk menolong teman-temannya dan hanya ada satu buku dongeng Si Kancil yang mencantumkan kesimpulan atau pesan moral.

Sementara itu, berdasarkan wawancara terhadap murid di TKQ Miftahul Hidayah, penggambaran karakter Si Kancil yang cukup dikenal dikalangan anak-anak ada pada film animasi Si Kancil produksi Les' Copaque asal negara Malaysia yang berjudul Pada Zaman Dahulu. Animasi ini menceritakan tentang seorang kakek yang mendongeng kisah Si Kancil dan teman-temannya. Kancil dalam film ini digambarkan pintar menipu untuk menyadarkan binatang yang jahat dan suka menyelakai binatang lainnya.

Dari beberapa hasil observasi di atas, mayoritas karakter Kancil yang sering "menipu" namun diberi label "cerdik" ini yang dianggap rentan bagi anak-anak. Karena adanya kesan ambigu terhadap perilaku baik dan buruk yang dilakukan oleh si Kancil. Berikut ini adalah observasi mendalam terhadap salah satu buku dongeng si Kancil yang berjudul Kancil Menipu Kera karya Tira Ikranegara yang diterbitkan oleh Aksara Press. Ibu In In, seorang pendongeng di Taman Kanak-Kanak Al Aqso, Sarijadi, Bandung ini mengatakan bahwa dongeng dalam buku tersebut memuat kekurangan yang perlu diperbaiki apabila ingin diberikan kepada anak usia 4-6 tahun, seperti pada segi visualnya, termasuk penggunaan warna dan ukuran gambar pada buku cerita yang kurang tepat, serta narasi yang perlu diperbaiki karena kata-kata yang digunakan cenderung kasar dan tidak adanya pesan moral.

Analisis Buku Dongeng Pengantar Tidur Dongeng Si Kancil dan Teori Sastra Anak 
Buku ini memuat kekurangan yang perlu diperbaiki apabila ingin diberikan kepada anak usia 4-6 tahun. Kekurangan itu dapat dikaitkan dengan penjelasan tabel sebagai berikut:

Tabel 1. Tabel Analisis Buku Dongeng Si Kancil dan Teori Sastra Anak. Sumber: Olahan Peneliti.

\begin{tabular}{|c|c|}
\hline ANALISA & \multirow{5}{*}{$\begin{array}{l}\text { PERBAIKAN } \\
\text { Kata berkonotasi } \\
\text { negatif lebih baik } \\
\text { dihindari dari } \\
\text { awal, terutama } \\
\text { apabila } \\
\text { digunakan dalam } \\
\text { judul sehingga } \\
\text { judul diganti } \\
\text { menjadi "Si } \\
\text { Kancil dan Si } \\
\text { Kera" }\end{array}$} \\
\hline "Kancil Menipu & \\
\hline Kaneill Menipu Kera & \\
\hline Ir $x \|$ il dir vil $b$ & \\
\hline $\begin{array}{l}\text { Kera" sudah menarik } \\
\text { perhatian anak tentang } \\
\text { menipu. }\end{array}$ & \\
\hline 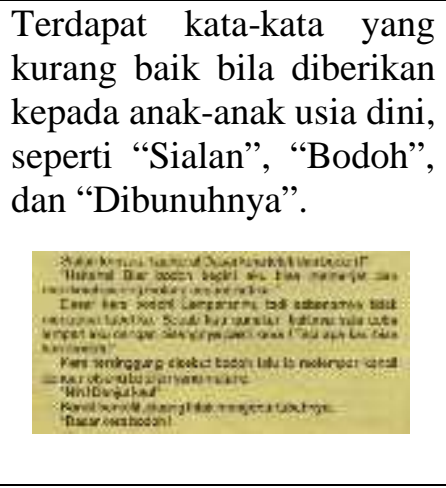 & $\begin{array}{l}\text { Anak usia dini } \\
\text { masih belum } \\
\text { mengerti tentang } \\
\text { baik buruknya } \\
\text { suatu bahasa. } \\
\text { Oleh karena itu, } \\
\text { kata-kata yang } \\
\text { kurang tepat } \\
\text { untuk anak lebih } \\
\text { baik dihindari } \\
\text { dan dihilangkan. }\end{array}$ \\
\hline $\begin{array}{l}\text { Tidak ada pesan moral } \\
\text { dalam cerita. }\end{array}$ & $\begin{array}{l}\text { Buku bacaan } \\
\text { harus dipilih } \\
\text { karena } \\
\text { mengandung dan } \\
\text { menawarkan } \\
\text { unsur moral } \\
\text { lewat tokoh anak } \\
\text { dengan nasihat } \\
\text { sebagai model } \\
\text { bertingkah laku } \\
\text { (Nurgiyantoro, } \\
\text { 2005:205) }\end{array}$ \\
\hline $\begin{array}{l}\text { Bahasa terlalu berat bagi } \\
\text { anak usia dini. }\end{array}$ & $\begin{array}{l}\text { Bahasa yang } \\
\text { digunakan anak } \\
\text { mengandung } \\
\text { kata-kata konkret }\end{array}$ \\
\hline
\end{tabular}

\begin{tabular}{|c|c|}
\hline 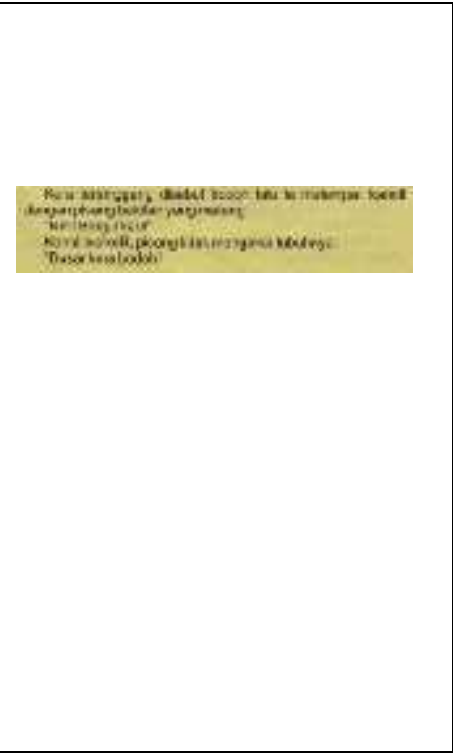 & $\begin{array}{l}\text { yang dapat } \\
\text { membentuk } \\
\text { perpautan bunyi } \\
\text { sehingga } \\
\text { menarik dan enak } \\
\text { untuk dibaca, } \\
\text { menggunakan } \\
\text { kalimat yang } \\
\text { sederhana, serta } \\
\text { penanda } \\
\text { hubungan } \\
\text { kalimat yang satu } \\
\text { dan yang lain } \\
\text { tampil secara } \\
\text { eksplisit. } \\
\text { (Mursini, } \\
\text { 2012:4) }\end{array}$ \\
\hline $\begin{array}{l}\text { Tidak ada penjelasan tokoh } \\
\text { yang baik dan tidak baik } \\
\text { untuk ditiru, sedangkan } \\
\text { kedua tokoh dalam cerita } \\
\text { berperilaku buruk, yaitu } \\
\text { mencuri. }\end{array}$ & $\begin{array}{l}\text { Penilaian tingkah } \\
\text { laku anak kecil } \\
\text { dibedakan ke } \\
\text { dalam baik dan } \\
\text { buruk } \\
\text { berdasarkan } \\
\text { hukuman dan } \\
\text { hadiah yang } \\
\text { diperoleh dari } \\
\text { orang dewasa } \\
\text { atau penguasa } \\
\text { (Nurgiyantoro, } \\
\text { 2005:203) }\end{array}$ \\
\hline $\begin{array}{l}\text { Kata-kata terlalu banyak } \\
\text { dan padat. }\end{array}$ & \multirow{2}{*}{$\begin{array}{l}\text { Kalimat panjang } \\
\text { dan padat bisa } \\
\text { sangat } \\
\text { menakutkan } \\
\text { untuk anak-anak } \\
\text { (Setiautami, } \\
\text { 2011:316). }\end{array}$} \\
\hline 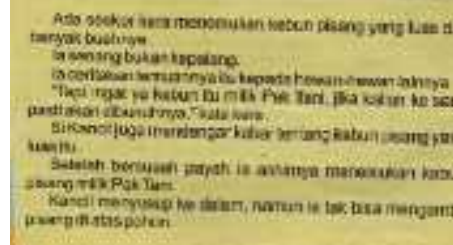 & \\
\hline $\begin{array}{l}\text { Gambar terlalu sedikit dan } \\
\text { kecil. }\end{array}$ & $\begin{array}{l}\text { Sajian tulisan dan } \\
\text { gambar digarap } \\
\text { secara } \\
\text { berimbang, } \\
\text { bahkan biasanya } \\
\text { sajian } \\
\text { gambarnyalah } \\
\text { yang lebih kuat. }\end{array}$ \\
\hline
\end{tabular}




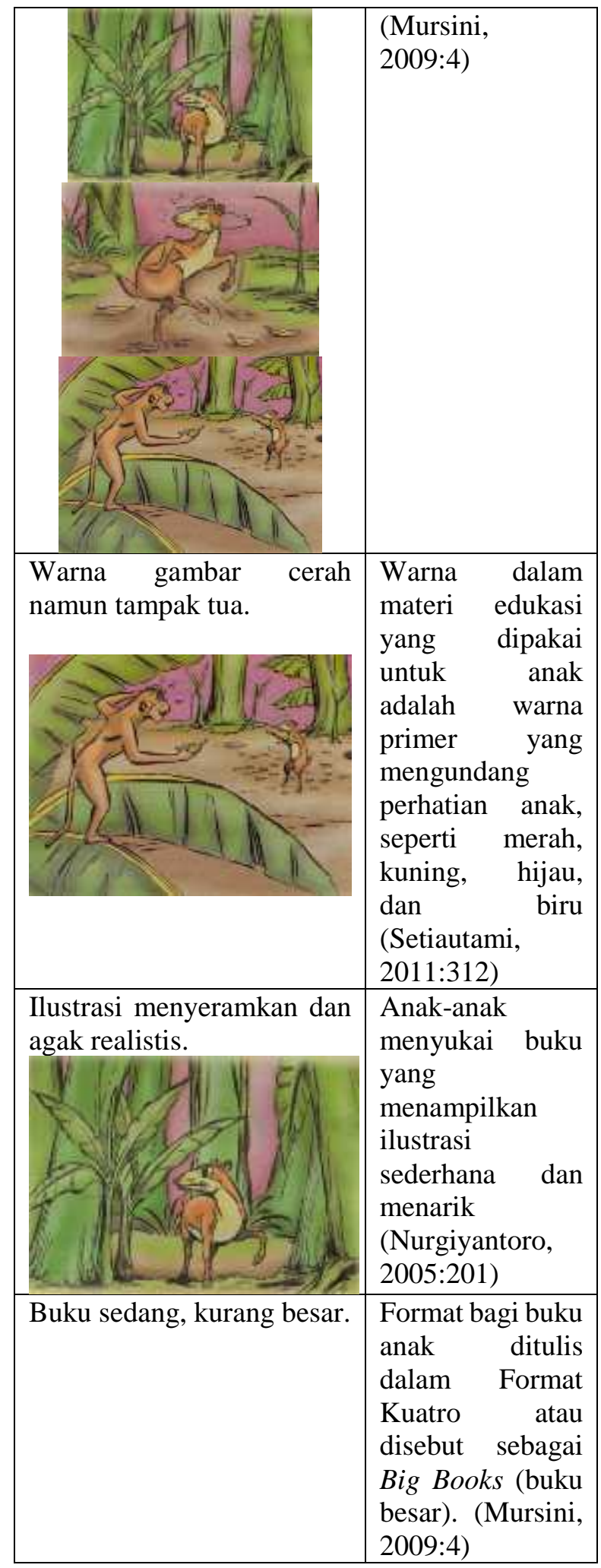

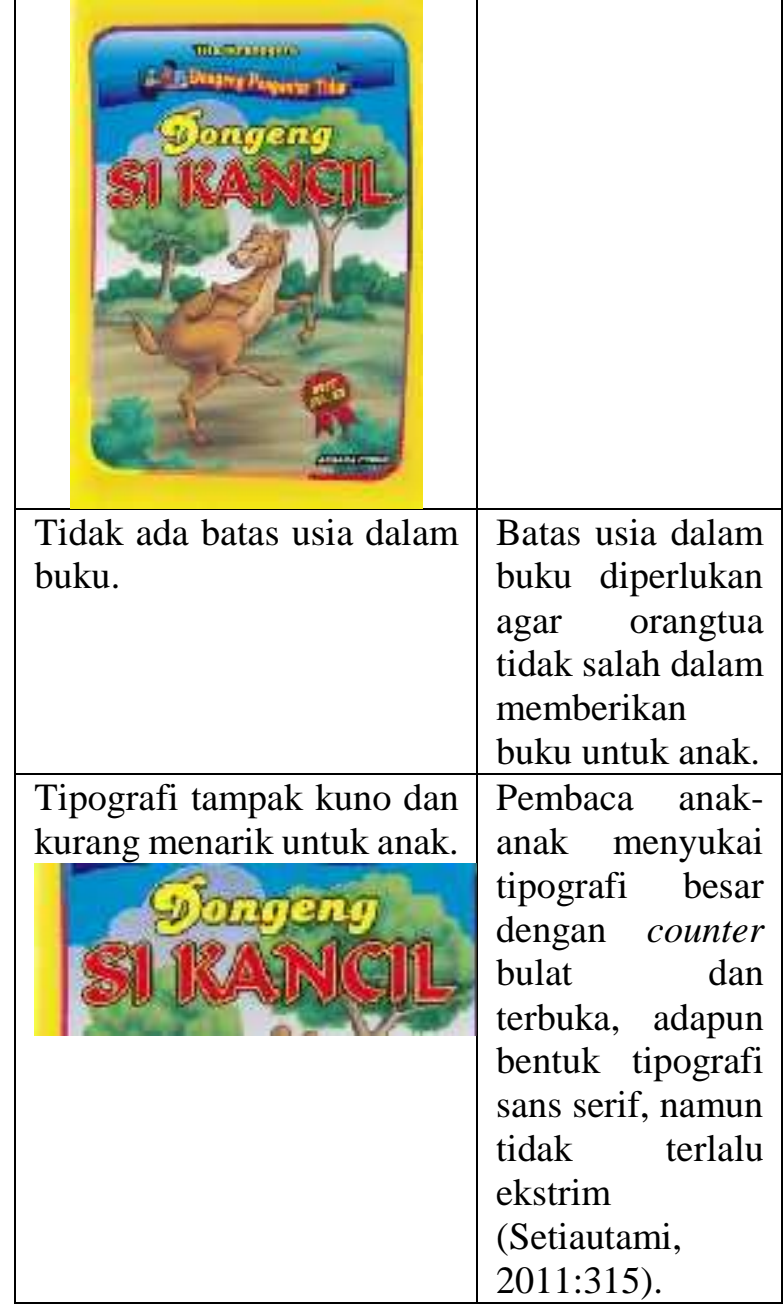

\subsubsection{Analisis SWOT}

1. Strength (Kekuatan)

Strength atau kekuatan ini menjelaskan tentang kelebihan atau keunggulan yang ada dalam buku Dongeng Si Kancil karya Tira Ikranegara. Kekuatan dalam buku tersebut antara lain:

- Dongeng yang disuguhkan adalah dongeng Indonesia zaman dahulu.

- Ada enam dongeng yang disuguhkan dalam buku.

- Harga buku murah dan terjangkau oleh kalangan menengah ke bawah.

\section{Weakness (Kelemahan)}

Weakness atau kelemahan dalam analisis SWOT merujuk pada kekurangan dalam suatu 
produk. Kelemahan dalam buku Dongeng Si Kancil antara lain sebagai berikut:

- Kekurangan pada buku terdapat pada kata-kata kasar, visual yang kurang menarik untuk anak, warna yang kurang mencolok, penggunaan tipografi yang kurang menarik dan penggunaan kalimat yang terlalu panjang.

\section{Opportunities (Peluang)}

Opportunities atau peluang menggambarkan kondisi baik untuk sebuah usaha agar dapat mengembangkan usahanya. Peluang untuk buku Dongeng Si Kancil ini adalah:

- Pembentukan ulang karakter dan tema dongeng si Kancil sesuai dengan perkembangan anak.

\section{Threat (Ancaman)}

Threat atau ancaman menjelaskan tentang tantangan atau ancaman yang bisa jadi penghalang untuk mengembangkan usahanya. Ancaman bagi buku Dongeng Si Kancil tersebut yaitu:

- Anak-anak lebih mengenal Si Kancil dari serial animasi Pada Zaman Dahulu di televisi karena lebih mudah didapat dan gaya visualnya yang menarik.

- Cerita anak dengan tema modern asal luar negeri lebih diminati anak daripada dongeng asal Indonesia.

\subsubsection{Analisis $5 \mathrm{~W}+\mathbf{1 H}$}

\section{What (Apa)}

What atau apa ini menjelaskan masalah yang dijadikan penelitian. Masalah yang ditemukan peneliti yaitu dongeng Si Kancil yang ada di Indonesia didominasi unsur cerita yang terkesan egois dan berani berbohong demi kepentingannya sendiri. Dongeng Si Kancil yang berjudul Kancil Menipu Kera karya Tira Ikranegara memuat kekurangan yang perlu diperbaiki, baik dalam segi visual maupun ceritanya.

\section{Who (Siapa)}

Who atau Siapa dalam analisis ini merujuk pada target audiens penelitian tersebut. Target utama penelitian ini adalah anak-anak TKQ
Miftahul Hidayah usia 4-6 tahun serta target sekundernya adalah guru-guru TKQ Miftahul Hidayah.

\section{Where (Dimana)}

Where atau Dimana menjelaskan tentang tempat yang dijadikan penelitian. Tempat yang diambil penulis adalah di TKQ Miftahul Hidayah, Jl. Ranca Herang RT.08 RW.01 Sarijadi Bandung.

4. When (Kapan)

When atau Kapan ini mengenai waktu terjadinya masalah tersebut. Waktu untuk penelitian ini adalah ketika dongeng-dongeng Si Kancil zaman dahulu yang memiliki cerita yang kurang baik untuk anak masih diceritakan serta ketika anak-anak masih suka menonton serial animasi Pada Zaman Dahulu di televisi.

\section{Why (Mengapa)}

Why atau Mengapa merujuk pada alasan masalah ini terjadi. Alasan dalam penelitian ini adalah karena buku dongeng Si Kancil di Indonesia sebagian besar masih belum memenuhi kriteria buku dongeng yang baik untuk anak usia dini.

\section{How (Bagaimana)}

How atau Bagaimana menjelaskan tentang cara peneliti mengatasi masalah tersebut. Cara penulis mengatasinya adalah dengan membuat ilustrasi cerita Si Kancil dan Si Kera yang telah disesuaikan dengan perkembangan psikologis yang berkaitan dengan teori visual dan teori sastra anak usia dini.

\subsubsection{Target Audience}

\section{Target Khusus}

- Demografis

Target utama adalah anak laki-laki dan perempuan murid TKQ Miftahul Hidayah usia 4-6 tahun dan target sekundernya adalah guru TKQ Miftahul Hidayah usia 30-40 tahun.

- Geografis

Target utama dan sekunder berlokasi di TKQ Miftahul Hidayah, J1. Ranca Herang RT.08 RW.01 Sarijadi Bandung.

\section{- Behavioral}

Ditujukan untuk anak-anak yang menyukai cerita Si Kancil serta untuk guru yang belum mengerti 
cara memilih buku dongeng yang baik untuk anakanak sesuai usianya.

\section{- Psikologis}

Target utama memiliki karakteristik aktif, ceria, dan powerfull, sedangkan untuk target sekundernya memiliki karakteristik penyayang, keibuan, ceria, dan penyabar.

\section{Target Umum}

- Demografis

Target utama adalah anak laki-laki dan perempuan usia 4-6 tahun dengan status anak adalah pelajar dan target sekundernya adalah orangtua/pembimbing bercerita usia 20-45 tahun dengan status mahasiswa/pekerja/pengajar.

\section{- Geografis}

Target utama dan sekunder berlokasi di Indonesia.

\section{- Behavioral}

Ditujukan untuk anak-anak yang menyukai $\mathrm{Si}$ Kancil serta untuk orangtua/pembimbing bercerita yang belum mengerti cara memilih buku dongeng yang baik untuk anak-anak sesuai usianya.

\section{- Psikologis}

Target utama memiliki karakteristik aktif, ceria, dan powerfull, sedangkan untuk target sekundernya memiliki karakteristik penyayang, dewasa, ceria, dan penyabar.

\section{PERANCANGAN}

- Warna

Warna yang digunakan dalam Buku Dongeng Si Kancil dan Si Kera adalah warna-warna dasar, karena disukai oleh anak-anak. Menurut Setiautami, "Warna dalam materi edukasi yang dipakai untuk anak adalah warna primer yang mengundang perhatian anak, seperti merah, kuning, hijau, dan biru" (2011:312). Warna-warna tersebut peneliti ambil dari sebuah gambar anakanak dan digambarkan oleh palet warna sebagai berikut.

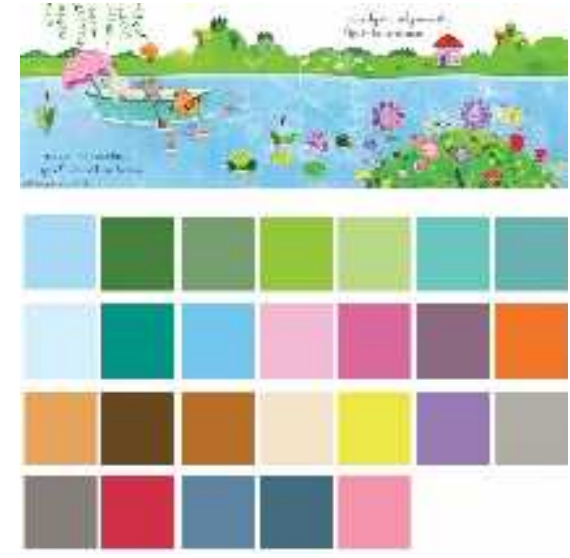

\section{Gambar 1. Pallete Warna Cerah (Primer).} Sumber: Olahan Peneliti.

- Tipografi

Tipografi merupakan salah satu elemen dalam desain grafis yang bisa dilihat sebagai ilustrasi atau kata yang dibaca. Ukuran font untuk anakanak terdiri dari beberapa tingkatan. Sutopo membuat tabel pedoman ukuran font untuk anakanak sebagai berikut:

Tabel 2. Pedoman Ukuran Font Anak-Anak Sumber: Sutopo dalam buku Desain Brosur dan Majalah dengan Adobe Indesign. (2007:22)

\begin{tabular}{|c|c|}
\hline Tingkat & Ukuran/Style Font \\
\hline $\begin{array}{c}\text { Taman-Kanak-Kanak- } \\
\text { Tingkat Pertama }\end{array}$ & 24 pt.bold \\
\hline Tingkat Kedua & 24 pt.plain \\
\hline Tingkat Ketiga-Keempat & 18 pt.plain \\
\hline Tingkat Kelima & 14 pt.plain \\
\hline
\end{tabular}

Penjelasan tipografi anak dalam jurnal yang sama mengungkapkan ciri untuk desain tipografi anak: "Counter harus bulat dan terbuka, tidak bersudut tajam atau persegi panjang" (Setiautami, 2011:315). Hal yang terpenting dalam desain tipogafi anak adalah desain yang mudah untuk dibaca oleh pembaca pemula. Kalimat yang sederhana dan baris yang sedikit diperlukan dalam buku pmbelajaran untuk anak-anak usia dini. Tipografi dalam buku dongeng adalah tipografi sans serif atau tipografi tanpa sirip/serif dengan 
font besar. Tipografi yang digunakan antara lain sebagai berikut:

- Kids

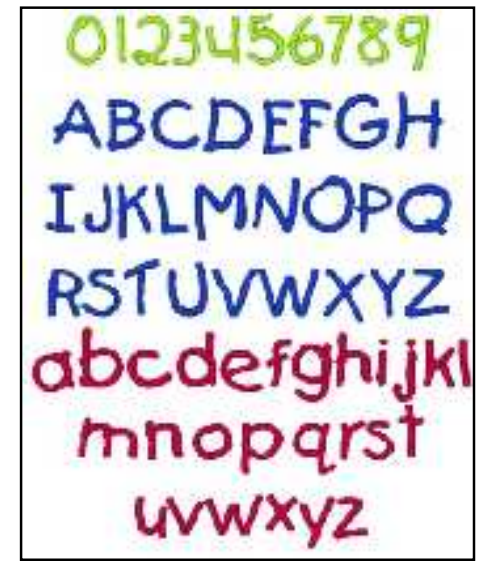

Gambar 2. Font Kids. Sumber: http://www.mirayacraft.biz

- Homework

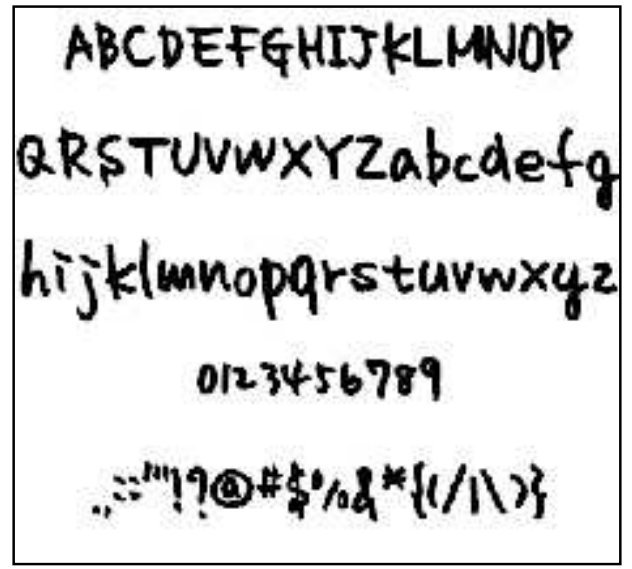

Gambar 3. Font Homework. Sumber: http://www.fontspace.com

- Ilustrasi

Ilustrasi adalah sebuah elemen dalam desain grafis yang digunakan untuk menggambarkan kata-kata yang mengiringinya. Ilustrasi anak-anak adalah ilustrasi yang menggambarkan suatu objek secara mudah dikenali dan dapat menarik minat anak. Anak-anak dapat mengenali sebuah objek meskipun digambar sangat sederhana, seperti gambar kaktus tanpa duri atau gambar sederhana lainnya. Gaya visual yang digunakan pada ilustrasi ini sederhana dan bersifat Ruang Waktu Datar (RWD) serta Naturalis-PerspektifMomenopname (NPM).

Ciri-ciri NPM adalah objek yang jauh di gambar kecil, sementara yang dekat digambar besar. Ditembak dari satu arah, satu jarak, satu waktu, seakan kita berdiri disatu tempat. Gambar jadi sebuah skena, objek dideskripsikan naturalis tanpa matra waktu, disebut juga sebagai gambar mati (still-picture) yang dibatasi dalam satu bingkai. Sistem NPM lebih dekat dengan ruang (space) fisika klasiknya Newton, dua dimensi hanya terdiri dari panjang dan lebar, sementara tiga dimensi terdiri hanya dari panjang-lebartinggi, semuanya tanpa matra waktu, namun menghasilkan ilusi ruang yang kuat. Sistem NPM ini dapat disebut universal, namun walaupun begitu setiap etnik memiliki cara yang berbeda dalam menggambarkannya (Tabrani, 2012: 3).

Ciri -ciri RWD adalah tiap objek bisa ditembak dari berbagai arah, berbagai jarak, berbagai waktu. Gambar jadi sebuah sekuen yang bisa terdiri dari sejumlah adegan. Besar atau kecilnya ukuran suatu objek tidak berhubungan dengan jarak namun berhubungan dengan penting atau tidaknya objek di dalam cerita. Dalam sistem RWD, suatu gambar bisa terdiri dari sejumlah latar dengan tiap latar memiliki ruang dan waktu masing - masing. Sistem ini lebih dekat dengan ruang (space) fisika modernnya Eintein (teori relatifitas) yang menyatakan bahwa ruang dan waktu tak terpisahkan (Tabrani, 2012: 4). Beberapa ciri lain sistem bahasa rupa RWD ini antara lain: belum mengenal 'ukuran pengambilan' maka setiap objek pada gambar umumnya digambar seluruh badan dari kepala hingga kaki. Jadi RWD lebih bercerita dengan gestur, sementara NPM bercerita lewat ekspresi wajah. Suatu objek digambar dengan menonjolkan karakteristik khasnya hingga mudah dikenali. Bila suatu kejadian penting diceritakan, maka digunakan cara 'sinar $\mathrm{x}$ ' atau tembus pandang, adanya cara menggambar 'ruang angkasa', cirinya objek digambarkan terbalik- 
balik, maksudnya ada suatu yang berkeliling, tiap objek dapat digeser seluruhnya atau sebagian hingga semua bagian nampak dan bisa diceritakan satu sama lain (Tabrani, 2012: 137).
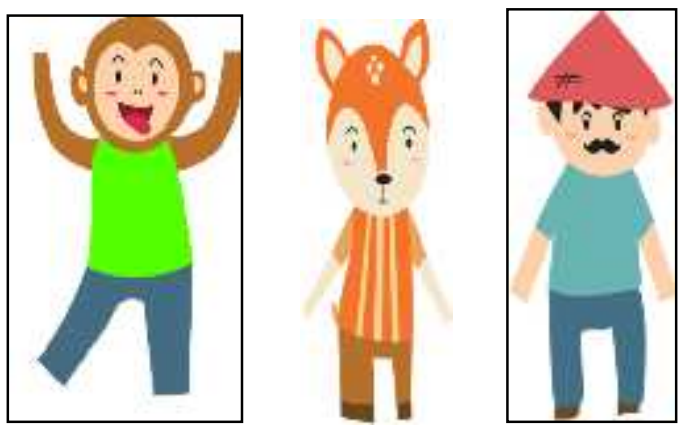

\subsection{Perancangan Ilustrasi Karakter Si Kancil,} Si Kera dan Pak Tani

Perancangan ilustrasi karakter utama cerita ini berdasarkan hasil presentasi angket yang dilakukan terhadap murid TKQ Miftahul Hidayah. Hasil Presentase dijabarkan kedalam diagram di bawah ini:

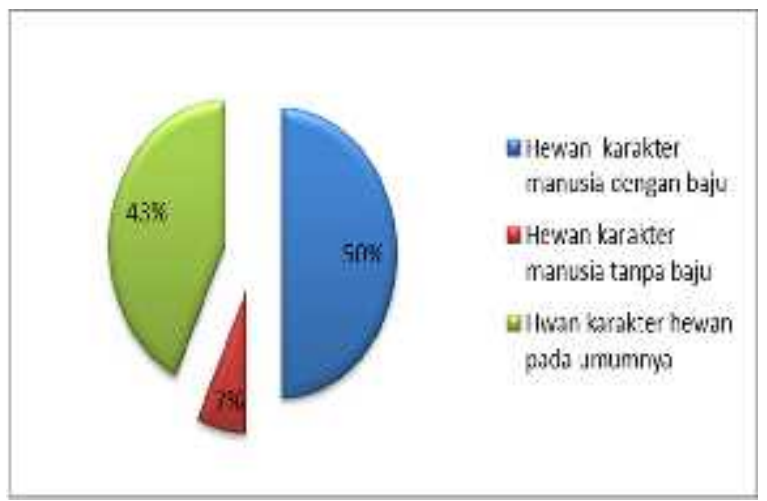

Gambar 4. Presentase Ilustrasi Favorit Anak TKQ MH

Sumber: Olahan Peneliti.

\section{Karakter Si Kancil, Si Kera dan Pak Tani}

Dari berbagai observasi dan pengembangan karakter tokoh-tokoh dongeng, maka ilustrasi karakter yang penulis buat dalam dongeng $\mathrm{Si}$ Kancil dan Si Kera adalah sebagai berikut.

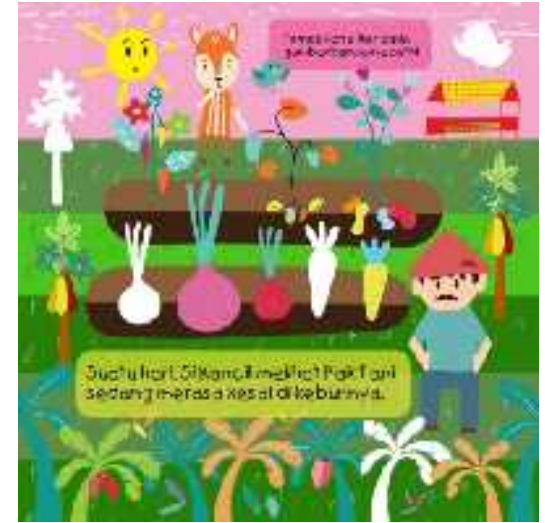

Gambar 5. Ilustrasi Si Kera, Si Kancil dan Pak Tani.

\section{Sumber: Olahan Peneliti.}

\section{.3.2 Story Line}

Storyline merupakan naskah dalam bentuk teks. Storyline untuk buku dongeng Si Kancil dan Si Kera adalah sebagai berikut:

- Pagi Hari, ada Si Kancil dan Pak Tani di Kebun Pak Tani.

Deskripsi: Suatu hari, Si Kancil melihat Pak Tani sedang merasa kesal di kebunnya (Halaman 1).

"Kenapa Pak Tani terlihat marah?" tanya Si Kancil. "Ada yang mengambil pisang saya tanpa izin, Cil," jawab Pak Tani (Halaman 2).

- Pagi hari, ada Si Kancil di dekat pohon jambu besar.

Deskripsi: Kancil merasa kasihan dan berniat menolong Pak Tani menemukan pencurinya (Halaman 3)

- Siang hari, ada Si Kancil dan Kera, di jalan dekat pohon.

Deskripsi: Tidak lama, Si Kancil melihat $\mathrm{Si}$ Kera sedang memakan pisang di pohon (Halaman 4).

"Hai, Kera! Kamu sedang apa?" tanya Si Kancil (Halaman 5).

"Aku sedang makan pisang, Cil. Enak sekali!" jawab Si Kera (Halaman 6).

"Darimana kamu mendapatkannya?" tanya Si Kancil lagi (Halaman 7).

$\mathrm{Si}$ Kera pun menunjukkan tempat ia mendapatkan pisang (Halaman 8). 
"Itu kan punya Pak Tani. Apa kamu sudah minta izin padanya?" tanya Si Kancil (Halaman 9).

"Belum. Aku langsung memakannya tanpa izin, Cil," jawab Si Kera (Halaman 10).

"Itu mencuri namanya. Kamu harus mengakui kesalahanmu," jawab Si Kancil (Halaman 11).

"Tidak Mau! Aku takut dimarahi Pak Tani, Cil," tolak Si Kera (Halaman 12).

- $\quad$ Siang hari, ada Si Kancil dan Si Kera, di Jalan ke kebun Pak Tani.

Deksripsi: Si Kancil pun mengajak Si Si Kera ke boneka orang- orangan di kebun Pak Tani (Halaman 13).

Sore hari, ada Si Kancil dan Si Kera, di Kebun Pak Tani.

Deskripsi: "Ayo minta maaf ke orang-orangan ini sebelum Pak Tani datang," kata Si Kancil (Halaman 14).

"Aku takut, Cil. Nanti kalau ada Pak Tani bagaimana?" tanya Si Kera (Halaman 15).

"Pak Tani tidak ada, kok," jawab Si Kancil (Halaman 16).

Si Kera pun mengakui kesalahannya kepada boneka orang-orangan Pak Tani (Halaman 17).

Sore hari, ada Si Kancil, Si Kera, dan Pak Tani, di kebun Pak Tani.

Desripsi: Tiba-tiba, keluarlah Pak Tani dari balik boneka orang-orangan itu.

Si Kera pun bersembunyi di belakang Si Kancil karena ketakutan (Halaman 18).

"Apakah kamu yang telah makan buah pisang milikku?" tanya Pak Tani (Halaman 19).

"Iya, Pak Tani. Maafkan aku," jawabSi Kera (Halaman 20).

"Tenang saja, Kera. Pak Tani tidak akan marah kalau kamu berkata jujur," kata Pak Tani (Halaman 21).

Pak Tani memberikan pisang kepada Si Kera dan Si Kancil (Halaman 22).

Sore hari, Si Kancil dan Si Kera, Di luar kebun Pak Tani.

Deskripsi: Si Kera pun berterima kasih kepada $\mathrm{Si}$ Kancil karena telah membantunya jujur kepada Pak Tani (Halaman 23).

\section{Implementasi Media}

4.8.1 Media Utama
Media utama yang digunakan untuk mengimplementasikan ilustrasi yang telah penulis buat adalah buku. Berikut ini beberapa contoh ilustrasi yang telah di layout ke dalam format buku.

\section{Sampul Buku}

Sampul buku menampilkan ilustrasi karakter utama dan elemen pendukung seperti tulisan judul dan synopsis cerita.

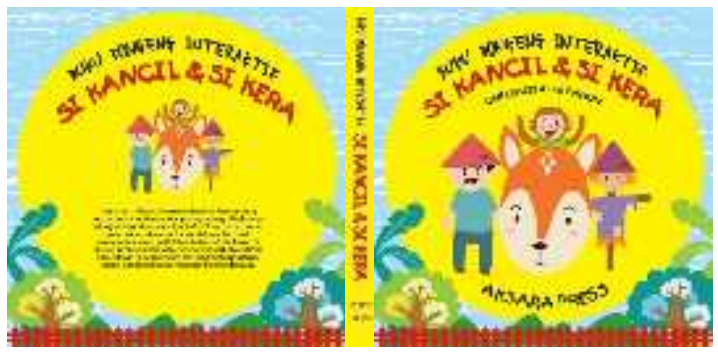

Gambar 6. Sampul Buku Si Kancil dan Si

Kera

Sumber: Olahan Peneliti.

\section{Halaman 1 Buku Si Kancil dan Si Kera}

Halaman 1 buku dongeng Si Kancil dan Si Kera ini bercerita tentang Si Kancil yang melihat Pak Tani sedang merasa kesal sebagai awal konflik di cerita tersebut.

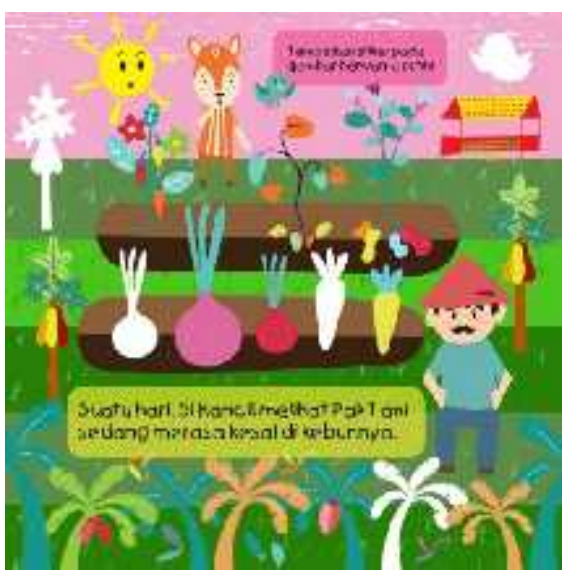

Gambar 7. Halaman 1 Buku Si Kancil dan Si Kera

Sumber: Olahan Peneliti.

\section{Halaman 2 Buku Si Kancil dan Si Kera}


Halaman 2 menceritakan tentang Pak Tani yang sedang mengungkapkan kekesalannya kepada pencuri yang telah mengambil pisangnya.

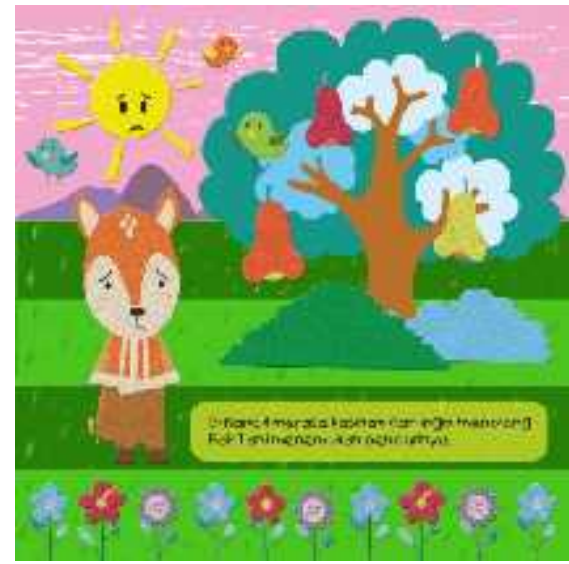

Gambar 8. Halaman 2 Buku Si Kancil dan Si Kera

Sumber: Olahan Peneliti.

\section{Halaman 3 Buku Si Kancil dan Si} Kera

Halaman 3 mengisahkan tentang $\mathrm{Si}$ Kancil yang merasa kasihan kepada Pak Tani dan ia merenung di dekat pohon jambu.

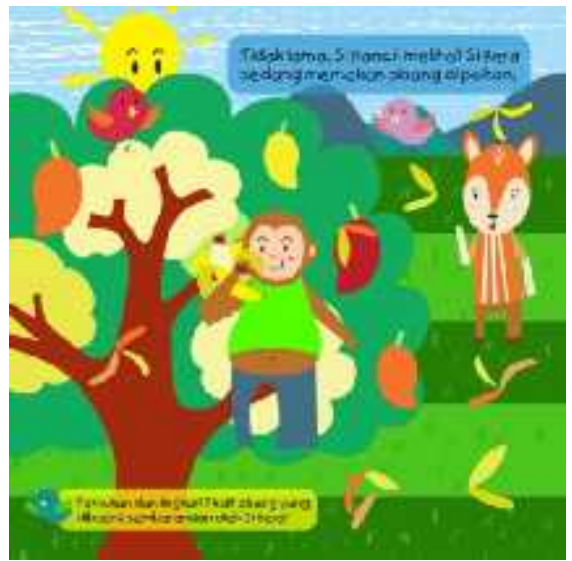

Gambar 9. Halaman 3 Buku Si Kancil dan Si Kera

Sumber: Olahan Peneliti.

\section{Halaman 4 Buku Si Kancil dan Si} Kera
Halaman 4 menceritakan

Si Kancil yang menemukan Si Kera sedang memakan pisang di pohon.

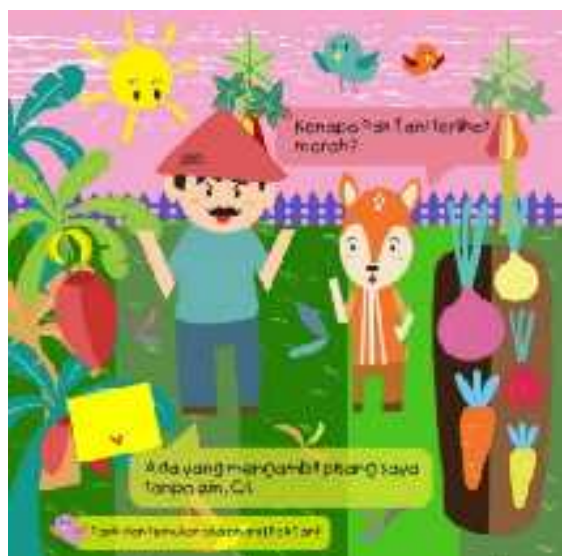

Gambar 10. Halaman 4 Buku Si Kancil dan Si Kera Sumber: Olahan Peneliti.

\section{Halaman 14 Buku Si Kancil dan Si Kera}

Halaman buku Si Kancil dan Si Kera yang ke-14 ini mengisahkan tentang Si Kancil yang mengajak Si Kera untuk meminta maaf kepada orang-orangan sawah sebelum Pak Tani datang.

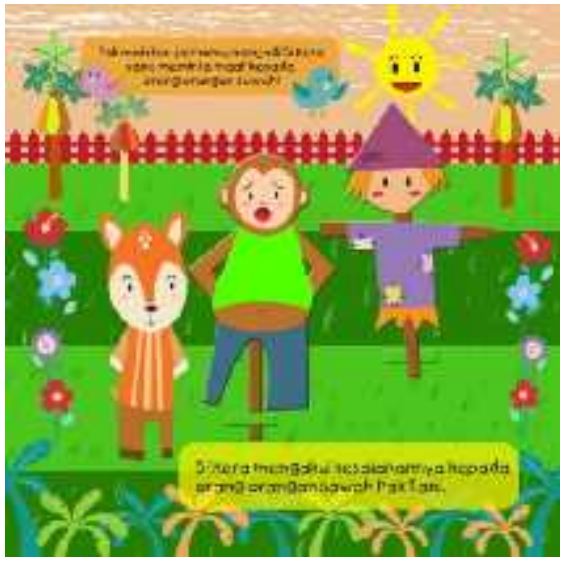

Gambar 11. Halaman 14 Buku Si Kancil dan Si Kera Sumber: Olahan Peneliti.

6. Halaman 17 Buku Si Kancil dan Si Kera 
Halaman 17 menceritakan tentang $\mathrm{Si}$ Kera yang meminta maaf kepada orangorangan sawah.

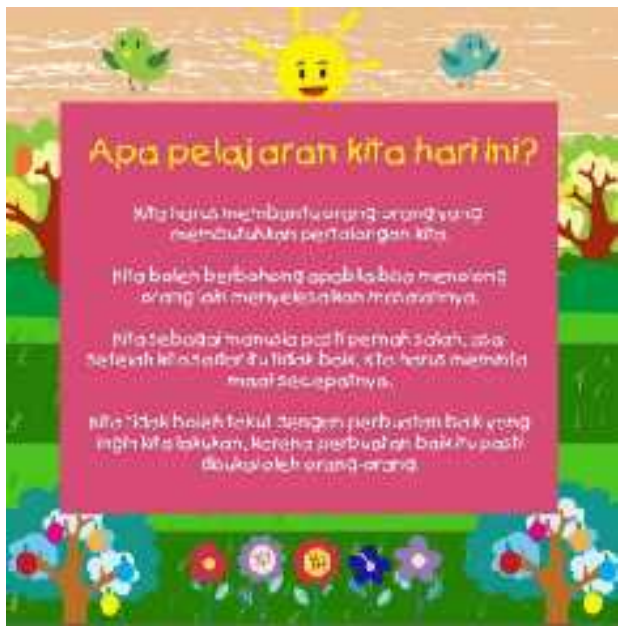

\section{Gambar 12. Halaman 17 Buku Si Kancil dan Si Kera Sumber: Olahan Peneliti.}

\section{Halaman 24}

Terdapat pesan moral diakhir cerita sehingga mempermudah anak-anak yang membaca sendiri maupun pembimbing bercerita untuk menarik kesimpulan dari cerita.

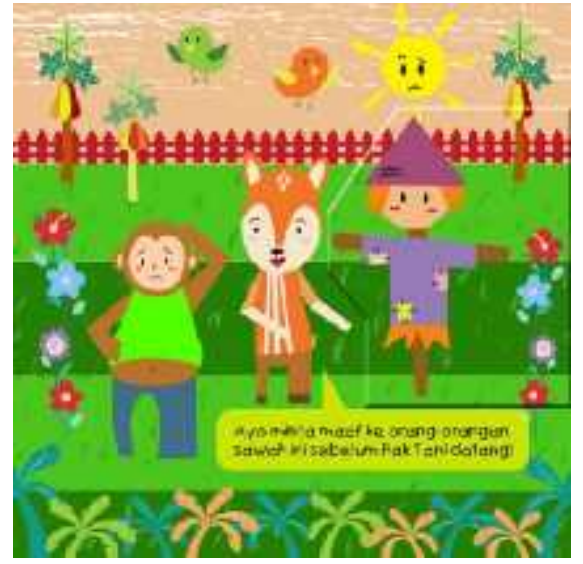

Gambar 12. Halaman Kesimpulan Sumber: Olahan Peneliti.

\section{KESIMPULAN}

Karakter Si Kancil dalam dongeng sudah menjadi hal yang tidak asing. Si Kancil yang memiliki karakter suka menipu ini masih menjadi perbincangan masyarakat Indonesia, karena dongeng-dongeng Si Kancil asal Indonesia masih kental dengan perilaku suka berbohong untuk kepentingannya sendiri. Hal ini bertolak belakang dengan karakter Si Kancil pada serial televisi Pada Zaman Dahulu, kartun asal Malaysia yang tayang di TV Indonesia. Tokoh Si Kancil dalam animasi tersebut digambarkan senang berbohong untuk membantu teman-temannya yang sedang kesulitan. Hal ini bila dibiarkan bisa membuat anak-anak memaklumi perilaku berbohong dan menipu. Maka, diperlukan perubahan pada konten dongeng Si Kancil.

Perancangan buku dongeng Si Kancil harus sesuai dengan kebutuhan untuk perkembangan anak-anak. Hal-hal yang harus diperhatikan mencakup tema cerita yang diambil, karakter dalam cerita, visual yang sesuai dengan minat target audiens, serta pesan yang ingin disampaikan. Dengan perancangan ulang ilustrasi buku dongeng $\mathrm{Si}$ Kancil dan $\mathrm{Si}$ Kera ini diharapkan anak-anak usia dini bisa mendapatkan edukasi yang baik melalui karakter Si Kancil sesuai perkembangan usianya.

\section{SARAN}

Perancangan buku dongeng Si Kancil untuk anak-anak usia dini tidaklah mudah. Perancang harus memikirkan aspek-aspek yang berkaitan dengan psikologi anak, visual anak, serta sastra anak. Ketiga aspek tersebut harus saling berhubungan agar dapat menghasilkan buku dongeng yang tepat untuk anak-anak usia dini.

Dongeng-dongeng Si Kancil asal Indonesia lebih baik diperkenalkan sejak dini agar anak-anak tahu bahwa cerita Si Kancil ini ada di Indonesia, bukan hanya di negara seberang yang telah lebih dulu mengemas dongeng Si Kancil dengan cerita yang baik serta mudah dijangkau anak-anak.

Konsep visual pada ilustrasi ini dapat pula diterapkan pada dongeng lain khas Indonesia. Sehingga penyajian dongeng sesuai dengan minat anak - anak Indonesia, juga tidak menutup kemungkinan untuk dikembangkan sesuai dengan perkembangan zaman. 


\section{DAFTAR PUSTAKA}

Asfandiyar, Yudha. 2009. Cara Pintar Mendongeng. Mizan Pustaka. Bandung.

Sutopo, Ariesto Hadi. 2007. desain Brosur dan Majalah dengan Adobe Indesign.

Jakarta: Elex Media Komputindo.

Tabrani, Primadi. 2012. Bahasa Rupa. Bandung: Kelir.

Musianto, Lukas S. 2002. Perbedaan Pendekatan Kuantitatif dengan Pendekatan

Kualitatif dalam Metode Penelitian. Jurnal Manajemen dan Kewirausahaan.4 (2): 125.

Mursini. 2009. Kontribusi Sastra Bagi AnakAnak. Jurnal Bahas. 14 (2): 4.

Nurgiyantoro, Burhan. 2005. Tahapan Perkembangan Anak dan Pemiihan Bacaan Sastra Anak. Cakrawala Pendidikan. (2): 201-204.

Setiautami, Dria. 2011. Eksperimen Tipografi Dalam Visual Anak. Humaniora. 2 (1). 312316.

http://www.mirayacraft.biz/font_kids.html diakses pada 10 April 2018.

http://www.fontspace.com/colorful-

typhoon/homework diakses pada 10 April 2018. 